\title{
Development of students' research activity under the conditions of contemporary information-oriented society
}

\author{
Tatiana G. Belova ${ }^{1, *}$ and Igor P. Belov ${ }^{1}$ \\ ${ }^{1}$ Moscow Technological Institute, 199334, Moscow, Russia
}

\begin{abstract}
Present article is to review an issue of students' research activity from the viewpoint of contemporary information age. It provides analysis of such concepts as "research", "research stand", "research skills", "research activity" and elicits the potential of research-based teaching under the conditions of present-day information-oriented society.
\end{abstract}

\section{Introduction}

Significance of such problem as development of students' research activity is stipulated by fundamentals of contemporary information age. Nowadays it is education being a driving power and resource of social and economic development, important way of innovation capacity formation for society and economy as well as of improvement of competitive capability of the country. Upgrading of Russian educational system should consider contemporary requirements of each person, society or state and demands for economic development based on the knowledge.

Dynamism of present-day world, information richness and rapid interchange of frameworks and technologies require the person to be initiative, flexible, capable of adopting nonstandard solutions and establishing efficient behavioral strategies.

In this regard education cannot be considered just of process of knowledge accumulation, but it should aim formation of creative approach to the surrounding environment, capability of making decisions and operate in accordance with constantly changing conditions.

The aforesaid facts make essential the problem of development of research activity.

High capabilities of elaboration the research activity in process of work with students (schoolchildren either students) is related to inspiration of interest, improvement of cognitive skills and thinking, ability of development knowledge independently and be familiar with contemporary information space.

Present day science contains predeterminations and certain humanitarian background for analysis and resolving of stated issue.

Scientific and theoretical approaches were developed in the sphere of development of personality through activity (K.A. Abulkhanova-Slavskaia, B.G. Ananiev, A.G. Asmolov, L.S. Vygotskii, E.S. Zair-Bek, V.P. Zinchenko, M.S. Kagan, A.N. Leontiev, S.L. Rubinstein, A.P. Tryapitsina, V.S. Shvyrev). Conceptual ideas of learning activity theory were defined (P.Y. Galperin, V.V. Davydov, I.A. Zimnyaia, I.I. Iljasov, I.Y. Lerner, N.F. Talyzina, G.I. Schukina, D.B. Elkonin). Methodology of scientific and pedagogical research is justified (Y.K. Babanskii, V.I. Zagviazinskii, V.S. Iljin, V.V. Kraevskii, M.N. Skatkin), and concepts were worked out regarding essentiality of development of research component in professional activity of teachers (V.I. Andreev, N.M. Zvereva, T.E. Klimova, I.Y. Lerner, A.K. Markova, A.M. Novikov, V.A. Sukhomlinskii). Concrete expression was given to approaches of establishing educational researching and exploration activity in educational institutions (V.M. Lizinskii, A.M. and O.M. Moiseevs, A.M. Novikov, M.M. Potashnik, T.I. Shamova). Defined were scientific theoretical understandings regarding research activity in the sphere of development of students' research activity (N.G. Alekseev, V.I. Andreev, I.A. Zimnyaia, M.V. Klarin, A.V. Leontovich, A.S. Obukhov, M.M. Rubinstein, A.I. Savenkov, A.N. Poddiakov). Problem of development of students' research activity is undertaken with due attention in studies of the foreign scientists (D. Brunsma, L. Cohen, F. Earl, W. Helsper, C. Hillbrandt, D. Levine, H. Ludwig, L. Manion, J. Miller, A. Ornstein, F. Peschel, W.Segall, T. Schwarz, A. Wilson) [1].

Notwithstanding large number of researches in reviewed pedagogic subject, general analysis showed that traditional forms of educational process organizing not always facilitate development of students'cognitive actions taken as participants of independent scientific inquiry. It depends on the following reasons:

- educational system is oriented on reproductive methods of training;

- low level of teachers preparation to organization of inquiry-based teaching;

- insufficient development status of methodical support for organization of students'research activity, taking in account levels of education, content and organizational forms of educational process. 
From the viewpoint of abovementioned issues it is very important to resolve today the issue of development of research activity of the students. A complex approach should be applied here, related with organization of socalled inquiry-based teaching.

Inquiry-based teaching presumes special approach to the education based on natural tendency of each person to independent study of surrounding world. Main task of inquiry-based teaching is that learner elaborates readiness and capability for independent creative mastering and reshaping of new types of activity in any sphere of human culture. [2]

Inquiry-based teaching is based on inborn cognitive need of a man. It presumes not fragmentary usage of research methods in education, but turning to principally new model of education in which priority positions belong to cognitive, research activity of the learner.

Inquiry-based teaching bears centuries tradition in foreign as well as Russian pedagogic theory and practice $[3,4]$. Although, according to organizational educational model prevailing through years the above mentioned type of learning was seldom applicable.

Final figuration of inquiry-based teaching concept happened in the second half of XIX-beginning XX (G. Spenser, G.A. Armstrong, T. Geksly, D.Dewy, V.A. Lie, P.F. Kapterev, G. Kersensteiner, S. Frene, R. Kusine, A. Demolen, A. Ferier, F. Vaskonsellos, A. Kay, m. Montessori, A. Parkherst, K.N. Ventcel, O. Dekroli, P. Kergomar, L. Gurlitt, A. Nill, U.K. Kilpatrick, A. Kollings). This period is peculiar with creation of educational models oriented to practical application of inquiry-based learning method [4].

Tendency to inquiry-based teaching in Russian pedagogic was strongly demonstrated in 20 -s, beginning of 30-s which resulted in its profound theoretical interpretation and active application in school practice (B.V. Vsesviatskii, B.V. Ignatiev, B.E. Raikov, K.P. Yagodovskii, V.F. Nataly, Y.I. Fausek, A.G. Kalashnikov, A.U. Zelenko, I.F. Svadkovskii). Although, in 30-s all development in this sphere was stopped. Active introduction of inquiry-based teaching into educational practice and further development of its theory happened at the end of twentieth century. Special attention is given to the spheres of pedagogical psychology and pedagogic where inquiry-based teaching is considered as one of efficient instruments which enable to reshape process of development of personality into self-development process (M.V. Klarin, A.V. Leontovich, A.S. Obukhov, A.N. Poddiakov, A.I. Savenkov).

Presently, interest towards inquiry-based teaching issues is represented by special fundamental research as well as by graded organization of research activity of the students.

\section{Analysis and Discussion}

Scientists consider ability for creative process and research activity as integral part of any type of human activity. These qualities constitute a prevailing basis of contemporary specialist professionalism and personally important aspect of personal becoming in culture [1].

Contemporary pedagogical science regards research activity of students as activity, related to seeking of resolution for creative research issue which solution is known well in advance (should be differed from practicum needed for demonstration a this or that law of nature), and which presumes main stages of scientific research: standardized problem statement according to the traditions customized in science; study of theory, dedicated to the subject; selection of research methods and their practical mastering; collection, analysis and generalization of material, own conclusions $[1,5]$.

Development of research activity of students represents dynamic process of personality growth, characterized by change in structural state of the students within stagewise acquiring of high potential of research activity, self-organization ands self-fulfillment.

In structure of research activity scientists define such components as "research", "research behavior", "research actions", "research stand".

The term "research" in daily use is normally understood as process of fresh knowledge cultivation being one of types of cognitive activity of a man. The source of research considered as type of activity lies within tendency to perception common for human nature.

Speaking about the role of research in science and education, the scientists $[5,6]$ compare notions "research" and "science" noting that spontaneous, unconscious research being a strong means of absorption the reality, is common for a man and always follows him notwithstanding his capabilities and social status. For a long time it may remain sporadic, unconscious. And only through science research becomes part of culture, acquires its history, methodology, institutions. With advent of science there appeared scientists' separate social group, which main activity is conducting research. In process of social development science gradually "privatizes" the sphere of research and social consciousness starts having a stereotype that research as a type of activity is restricted by science only.

A.V. Leontovich suggests differentiation between research as ideal type of activity directed to seeking of absolute truth, and its modern institutional form, namely, science: "We have discovered that research is a "pure", originally characteristic for a person way of reality perception, which becomes a cultural aspect only after appearance of science. Therefore, speaking about development of reality perception skill with students we can talk about "pure" research as mental activity outside of science... Addressing science we consider it as part of culture on the basis of which education is conducted" [5].

In modern world research as a way of reality perception loses its exclusive belonging to the sphere of science. At the same time, research as a way of reality perception might have a significant part, because it may help in resolving issue of development of new approaches, based not on acquiring of sum scope of readily available knowledge, but on methods of acquiring. It is more important in conditions of rapid 
increasing of overall knowledge of humankind and primary need for each person to master principally new majors and types of activities.

In due course education may become the most significant sphere of realization of heuristic research potential. That is why it is important to concentrate efforts on developing methods of introduction of research as activity type into educational sphere by means of elaboration of appropriate educational technologies: "This is the reason making a training research we should come back to the science, its history and methodology in order to build up cultural succession of development of research type of activity; and together with that differentiate and limit it from science to ease its institutionalization in the sphere of education as longknown way of reality perception and organization of educational activity" [5].

In comparing notions "research" and "research activity" it is notable that the latter also means not only procedurality and effectiveness but also structural organization and what is most important, subjectivity of this activity.

Research activity is a separate type of intellectual and creative activity, arising as a result of mechanisms of exploratory actions and based on research behavior. Still, whereas exploratory actions are determined solely by the fact of searching in conditions of uncertain situation and exploratory research behavior mainly external context of object functioning in this situation, research activity characterizes the very structure of this functioning. Research activity includes motivating factors (exploratory actions) of research behavior and mechanism of its realization. The role of such mechanism is performed by brainwork [2].

Research activity is not limited by exploratory actions, as it also includes analysis of obtained results, evaluation of further developments, forecasting (formation of hypothesis) of further elaborating.

Research activity is based on research actions and research behavior, but unlike the latter it is conscious, goal-oriented, and built-up by ways and means of culture [7].

Significance of sense of research activity in development of personality may be recognized only through understanding interior properties of research and its phenomenology.

Research phenomenon as per A.S. Obukhov include the components which correspond to factors of personality development:

- biological presuppositions (research actions, research behavior);

- development conditions (social and cultural, historically formed contexts which assist or hamper transferring of research behavior into research activity, stating norms and means for realization of this activity);

- inner position (worked out capacity of the person to search and recognize problems; consciously, creatively and in a constructive way respond to the problem, buildup research attitude towards the world, others and oneself).

Biological factors of research behavior manifestation are due to the fact that each person in his nature is a researcher. Research reflex is a basic property of mind. In his early age a man has research behavior that is similar with that of animals' with elementary thinking activity. But in course of growing-up social and cultural component becomes prevailing which transforms research behavior into research activity. "On definite stage at reasonable ratio of research initiative and social and cultural norms of realization of exploratory actions in form of research activity, a research stand of a person may be formed" [7].

Speaking on social and cultural determinants of research activity A.S. Obukhov noticed that research activity development mostly depends on intensity and variability of the realities of human existence, as well as the extent to which socio-cultural norms laid down the value of human research actions in collaboration with these realities.

In the absence of such standards research actions are manifested only in the form of situational spontaneous interaction with the environment, and research behavior will not unfold in complexly conscious activity. Standards of research behavior (or opposition to it) are reflected in the tradition of family education, games and folklore texts such as tales, proverbs and sayings.

The effectiveness of the research activities related to the development of a research position of the person. This is a significant personal basis, on the basis of which a person is not just responsive to changes in the surrounding world, but it has a need to look for the unknown, and after finding a situation that requires the implementation of research activities, consistently pass the main stages of the study [7].

Research position appears and develops in the course of research activities. "Significantly it is to develop of research position on the basis of which the person will solve the problematic situation and build his way in the world, was at the forefront in the organization of research activity of students" [7].

Thus the understanding of the phenomenology of the research allows us to see the basic meanings of research activities for the development of the individual.

But the realities of the modern information society highlight the significant potential that lies in the theory and practice of inquiry-based learning.

In contemporary conditions of information space actual skills and personalities which developed in course of the process of research training aimed to involve students into research activity.

First of all it concerns such an important concept as research position of the person. This developed research position allows a person to interact successfully with the changing realities of the world. If a person stops responding to research positions at a variety of issues, it becomes not ready to significant life changes.

Concerning the person staying in the open information space it is very important to possess by special research skills.

Research skills mean intellectual and practical skills needed for successful research activity.

This ability to identify the problem and solve it, hypothesize, observe, conduct experiments, analyze the events and the facts, make inferences and conclusions, 
structured material, summarize the results of studies to analyze the work done to assess the results of the study etc. [1].

Research skills are the foundation of the development of behavior based on the dominance of research actions manifested in different situations.

Finally, reflexive skills, formed in the course of research activities, are just as important in the realities of the modern IT-concentrated educational environment. Reflective skills are associated with the ability of the individual to the critical evaluation of the results of its own activities. Reflection is a process of analyzing the results of operations, problems, difficulties or success, as a result of which there is understanding of the essence of problems or difficulties are born new prospects for their resolution. That is, reflective skills allow formulating objectives and results of future activities, including education and that ensures its success.

Thus personal formations, abilities and skills acquired in the course of research activities are extremely important in today's information society because they allow the person to navigate in a complex information environment and to build a loyal behavior patterns in fast-changing environment.

For a person with a developed research activities tend to novelty-seeking and independent search for truth, the desire to go beyond the existing, already obtained knowledge.

It proves that the appeal to the educational resources of research teaching, theory and practice gained world pedagogical thought, identifying ways of efficient organization of research work of students is extremely important in today's open, information-saturated environment of education $[8,9]$.

\section{Conclusion}

Research activity development of students in contemporary conditions concerns resolving the following issues:

- Development of content-functional part of process of research activity development of students according to competence based framework of contemporary education;

- Optimum ratio of regulatory and creative part of research activities as an educational technology;

- Teachers training in organization of research education;

- Creating conditions for the development of personality research positions;

- Active introduction of information technologies in educational process

\section{References}

1. T.G. Belova, The development of students' research activity in Montessori Education (Press, Orenburg, 2012).

2. A.I. Savenkov, Research teaching and engineering in modern education, S. Res. W., 1, 22 (2004)

3. I.P. Belov, T.G. Belova, The development of the research method of teaching in the Russian pedagogical science and practice of XVIII-XIX centuries, W. of Sci. dis., 11(6), 2380 (2014)

4. I.P. Belov, T.G. Belova, The formation of the idea of the research method of teaching in foreign pedagogy until the middle of the XIX century, K. Sci., 12, 232 (2013)

5. A.V. Leontovich, The research activity as the basis for the educational activities construction (People Education, Moscow, 2001).

6. G.P. Shchedrovitsky, Philosophy. Science. Methodology (Idea, Moscow, 1997)

7. A.S. Obukhov, Person's research position, S. Res. W., 1, 61 (2006).

8. I.V. Osipov, E. Nikulchev, A.A. Volinsky et al., Study of Gamification Effectiveness in Online eLearning Systems, International Journal of Advanced Computer Science and Applications, 6(2), 71-77 (2015)

9. E. Pluzhnik, E. Nikulchev, Laboratories in cloud infrastructure of educational institutions, 2014 2nd International Conference on Emission Electronics (ICEE), 67-69 (2014) 